\title{
Stakeholders' responses to the use of innovative water trading systems in East Anglia, England
}

\section{M Lambroso ${ }^{1}$, C Twigger-Ross ${ }^{2}$, J Raffensperger ${ }^{3}$, J J Harou ${ }^{4}$, M Silcock ${ }^{5}$, and A J K Thompson ${ }^{5}$}

${ }^{1}$ HR Wallingford Ltd, Howbery Park, Wallingford, Oxfordshire OX10 8BA, UK

2 Collingwood Environmental Planning, Unit 1E, The Chandlery, 50 Westminster Bridge Road, London SE1 7QY, UK

${ }^{3}$ JFR Decision Research Ltd., 1126 Marine St., Santa Monica, California 90405, USA

4Department of Civil, Environmental and Geomatic Engineering, University College London Gower Street, London WC1E 6BT, UK

5 Anglian Water, Ambury Road, Huntingdon, Cambridgeshire PE29 3NZ, UK

Published in Water Resources Management, 2014, vol. 28, issue 9, pages 2677-2694.

The original publication is available at www.springerlink.com

\section{Abstract}

It is widely recognised that the current abstraction licensing system in England needs to be reformed to meet the challenges of future environmental flow requirements, likely increases in water demands and climate change. The UK Government has committed to the reform of the abstraction regime in England and work is underway, including the Welsh Government, to assess the impacts of different reform options, working closely with stakeholders. International experience reveals that the complexity of water management at a national level lends itself to common principles but ultimately that local solutions are required at a catchmentlevel to manage such challenges. Historically the number of abstraction licences traded in England is negligible. In the future the trading of abstraction licences and derivative water rights, for example water quotas, could play a key role in improving water use efficiency.

This paper describes research that was carried out to add to this evidence base in the Upper Ouse and Bedford Ouse catchment in East Anglia with a number of stakeholders to document their response to two innovative water trading systems which have been termed "improved pair-wise" trading and the "common pool" approach. Improved pair-wise trading would allow for a hierarchy of types of short-term abstraction licence trades. Some trades between specific points in a catchment might be pre-approved if the risks to the environment were deemed acceptable. The common pool approach is based on the trading of water quotas, using "smart market" methods, which enable economic optimisation of market outcomes based on abstractors' bids subject to realistic hydrological constraints. This method would allow all abstractors to bid into a common pool on a weekly basis to obtain their water. Both methods were demonstrated via two workshops to investigate the barriers and facilitators to water trading in practice. Participants were cautiously interested in the benefits offered by both methods, especially the ability to trade water at short notice. However, for these trading methods to play a key role in the reform of abstraction licensing the abstractors must have sufficient confidence that the underlying methods are sufficiently equitable, reliable and accurate.

Keywords Abstraction licensing; Abstractors; Stakeholder participation; Water markets, Water trading 


\section{Introduction}

In England the Environment Agency is responsible for deciding the maximum amount of water that can be taken ("abstracted") for use by people and businesses without excessively affecting the environment. The abstraction of water from surface and ground water sources is regulated by the Environment Agency via a licensing system that requires abstractors ${ }^{1}$ who take more than $20 \mathrm{~m}^{3}$ of water per day from the environment to have an abstraction licence (Environment Agency and Ofwat, 2011). The current abstraction licensing regime in England is likely to come under increasing pressure in the future as a result of:

- Climate change leading to a decline in water availability;

- The imposition of stricter environmental standards in order to meet the requirements of the Water Framework Directive (WFD);

- Increasing water demand as a result of population growth.

The development of economically efficient, flexible and sustainable approaches to allocating water resources between competing uses is vital for continued economic and social development. However, in England as in most countries, flexible market-oriented mechanisms play little or no role in allocating water. Globally, water is still often allocated based on political mandate or outdated administrative arrangements (National Water Commission, 2011).

The UK Government has committed to the reform of the abstraction regime in England and work is underway, including the Welsh Government, to assess the impacts of different reform options, working closely with stakeholders (Defra, 2012). One possible reform of the abstraction licensing system is to introduce methods that help to facilitate the trading of water. Well-designed water markets can deliver significant benefits in any system where water access is scarce by signalling the value of water dynamically (National Water Commission, 2011). This paper describes the response of stakeholders in a case study catchment in East Anglia in the east of England to two innovative methods which could help to make the trading of water simpler in the future. Before discussing the results of the research this paper gives an overview of how the abstraction licensing regime in England has developed over the past 50 years which has led to the need for its reform and the background to the two trading systems.

\section{The historical background to abstraction licensing in England}

The 1963 Water Act was the first to require that the right to abstract from surface or groundwater (with some exemptions) was subject to a licence. 'Permanent' licences conferring legal rights to take water were issued to riparian occupiers (whose right to water had hitherto been considered part of their right to land), on a 'first come, first served' basis, without formal guidelines for justification of required quantities. This reflected the perception of water as a free and plentiful resource, and followed the long established 'riparian rights' principle (Sowter and Howsam, 2008). This system of grandfathering abstraction rights was not designed to safeguard the environment or to manage competing demands. Grandfathering of existing abstractions as 'Licence of Rights' in the 1960s implicitly assumed practices that had gone unchallenged under common law were not impacting other legitimate users and were therefore acceptable. Licences were issued in perpetuity without flow restrictions and authorised a volume of abstraction derived from evidence of the previous three years' abstraction. Although it appeared to be pragmatic this led to organisations inflating the amount of water that they used (Cunningham, 2002).

\footnotetext{
${ }^{1}$ There are exemptions for dewatering, navigation and irrigation other than spray irrigation purposes (which is already subject to licence control) and transfers into Internal Drainage Board areas, the filling of vessels, e.g. for ballast water, fire fighting and to test water.
} 
Many changes have taken place since 1963; however, the legacy of the initial distribution of water rights on the current abstraction licensing system has limited the efficiency of water use (Cunningham, 2002). Nationally, approximately $80 \%$ of abstraction rights have been granted in perpetuity (Frontier Economics/Anglian Water, 2011).

Across England and Wales, about 21,000 abstraction licences enable the holders to draw water from surface and groundwater sources. Excluding public water supply companies, the largest group of abstractors is the power generation sector, although other industrial users are also large water abstractors. Agriculture accounts for around 1\% of abstraction on average across England and Wales, although this proportion varies considerably between regions and seasons (Environment Agency, 2009).

Some abstraction licences have a hands off flow or level condition that allow the Environment Agency to reduce or stop abstraction when surface water flows or groundwater levels fall below a specified threshold. Around $40 \%$ of surface water licences and $3 \%$ of groundwater licences contain these conditions (Environment Agency, 2012). Overall, one quarter of abstraction licences are subject to a flow or level restriction (Environment Agency, 2012). This figure reflects the fact that many older licences did not contain hands off flows.

During a drought the newest abstractors are restricted first, thereby protecting the environment and those with historical abstraction rights. As flows fall, other restrictions come into force. The final set of unrestricted abstraction licence holders can continue abstracting until a drought order is imposed (Environment Agency, 2012). Most abstractors pay operational licence fees based on the size of their licence, not on how much water they actually use. Hence, the current abstraction regime does not encourage efficiency of use or equitable distribution of water.

Current licensing arrangements are unlikely to deal efficiently with extended periods of water scarcity and greater volatility of supply. To prevent damage to the environment, licensed abstractions may need to be reduced. Good water allocation methods are thus all the more important for maximising the value of water (Frontier Economics/Anglian Water, 2011).

\section{The current system of water abstraction licence trading in England}

In November 2003 the British Government passed the Water Act 2003. This made the administration for making applications, transferring and renewing abstraction licences simpler and also reduced some of the barriers to the trading of water rights. Water abstraction licence trading is defined by Department for Food, Environment and Rural Affairs (Defra) and the Environment Agency as the transfer of licensable water rights from one party to another, for benefit (Environment Agency, 2011). As the regulator, besides from deciding whether the trade will engender unacceptable environmental consequences, the Environment Agency remains impartial during trades. As such, the current approach to water rights trading in England and Wales is the same as in all other countries where water trading occurs: an environmental regulator decides whether or not to approve proposed pair-wise trades. The terms of the transaction are up to the parties involved and the Environment Agency does not gather information on pricing or act as the broker. The current system can be characterised as bilateral or pair-wise trading with considerable transaction costs owing to the paper work involved and the time to complete a trade, which is typically six months. Administrative fees are only $£ 135$, but hiring expertise to assist the trade and the time involved to complete it can add significantly to the costs (Environment Agency, 2011). 
There is substantial scope for water trading. For example, within the agricultural sector, a large number of licences have not been used for many years. In theory, trading from farmers with "spare" water to those needing additional supplies, either in the short or long-term, would benefit both parties. For some, major barriers include the complexity and time to get trades approved. For others, the fear that the licence will be further restricted by the Environment Agency because of a sale or lease is a major constraint. Only 51 trades took place between 2003 and 2011 (i.e. about $0.25 \%$ of the available licences were traded in eight years) (Defra, 2011b, 2011c).

\section{Details of the trading systems researched}

To assist in informing Defra's policy reforms two innovative abstraction licence trading systems were researched as follows:

- An improved pair-wise trading system;

- A "smart market" or common pool method.

\subsection{Improved pair-wise method of trading}

The current abstraction licensing trading system in England comprises bilateral (or pair-wise) trades between two licence holders. Currently pair-wise trades of abstraction licences comprise two steps:

1. An abstractor wanting to buy or sell water rights must search for and make arrangements with another licence holder;

2. The trade must be approved by the Environment Agency.

The current arrangement of pair-wise trading is shown diagrammatically in Figure 1.

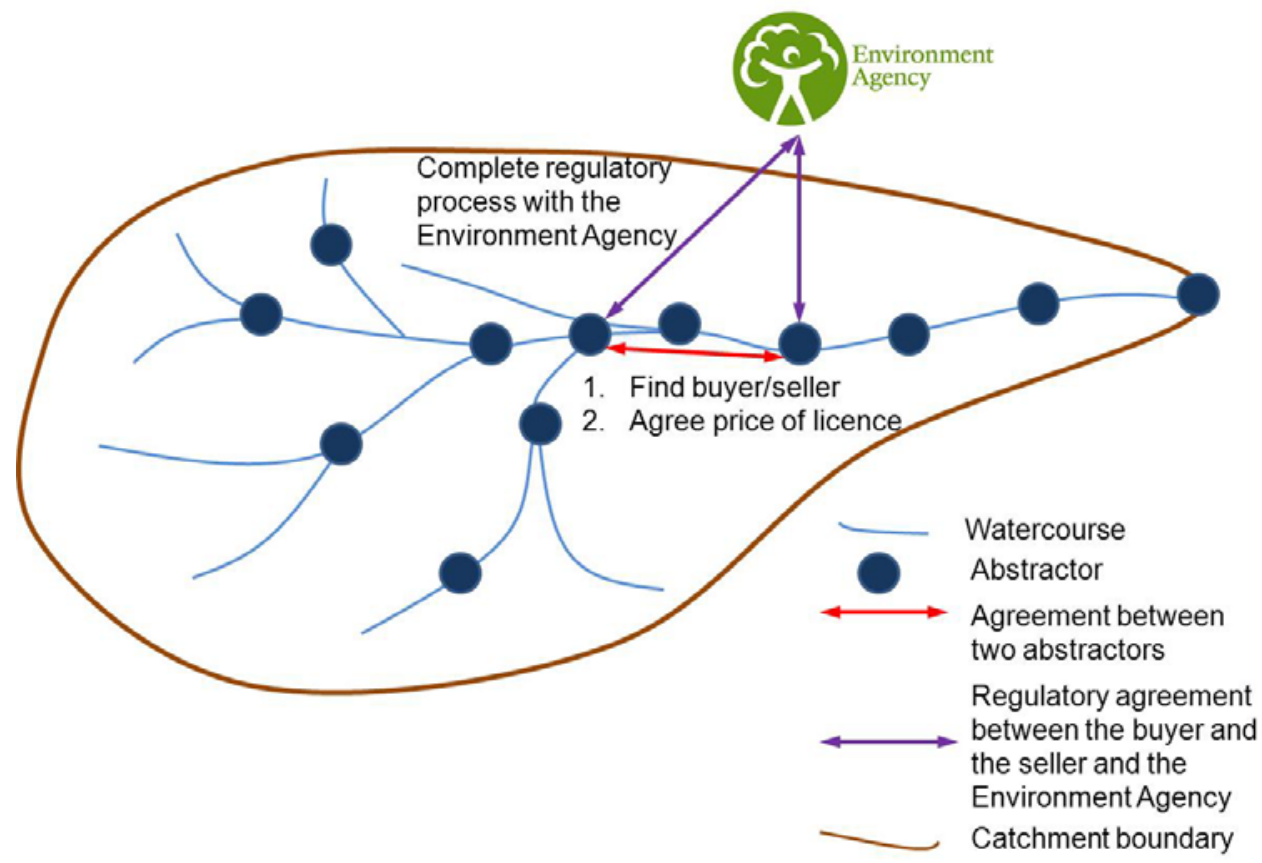

Figure 1 Pair-wise trading within a catchment 
Initiating a trade and getting regulatory approval takes on average six months. By improving the current system, trading would still be regulated, but could be less bureaucratic and time consuming than it is currently. Improved pair-wise trading is an incrementally improved version of the status quo that would include improved information and a faster processing of trade applications. The system would provide abstractors with more transparent information. The approval of a proposed trade would be much faster in most instances and less costly, thus addressing the current major barriers to abstraction licence trading.

Currently there is no simple method of abstractors ascertaining who in their catchment is willing to trade. Often trades are set up via informal mechanisms (e.g. word of mouth, phone calls). This search for a buyer or seller is a significant component of the transaction 'friction' i.e. the factors that tend to reduce water trading. More trades might occur if potential buyers and sellers knew of each other's interest in a potential transaction. One way to achieve this is through a water trading bulletin board, maintained for example by the Environment Agency or a third party, that would post offers to buy or sell water (i.e. certain volumes at certain times).

In an improved pair-wise trading system, it may be possible to identify potential trades or categories of trade (for example by direction or location) that are considered unlikely to create adverse effects, based on an appropriate hydrological and water management analysis. Trades falling into these categories could be either pre-approved or approved very quickly. Potential trades could be arranged into different classes with regards to their pre-approval, such that the pre-approval for each class is of a different duration. A hierarchy of trades could then be set up. An example of this is shown in Table 1. Pre-approved trades could be linked to a trading bulletin board with a data-base of pre-approved trades that would facilitate the processing of trade requests and allow geographically based visualisation tools to assist regulators and traders alike. 
Table 1 Example of a possible hierarchy of pre-approved trades

\begin{tabular}{|c|c|c|c|}
\hline $\begin{array}{l}\text { Category } \\
\text { of trade }\end{array}$ & Details of the trade & $\begin{array}{l}\text { Approval } \\
\text { time }\end{array}$ & $\begin{array}{c}\text { Duration of for } \\
\text { which the trade is } \\
\text { valid }\end{array}$ \\
\hline Green & $\begin{array}{l}\text { The buyer is downstream of the seller in } \\
\text { an area where water is available and the } \\
\text { buyer has an equal or inferior level of } \\
\text { water consumptiveness. Negligible } \\
\text { probability of environmental damage. }\end{array}$ & $\begin{array}{l}\text { Approved } \\
\text { automatically }\end{array}$ & Up to three months \\
\hline Yellow & $\begin{array}{l}\text { The buyer is downstream of the seller in } \\
\text { an area where water is available and the } \\
\text { buyer has an equal or inferior level of } \\
\text { water consumptiveness. Low probability } \\
\text { of environmental damage. }\end{array}$ & $\begin{array}{l}\text { Approved } \\
\text { automatically } \\
\text { for short term } \\
\text { trades }\end{array}$ & Up to one week \\
\hline Orange & $\begin{array}{l}\text { Similar to the existing system of trading } \\
\text { abstraction licences. Requirement for a } \\
\text { hydrological and environmental } \\
\text { investigation }\end{array}$ & $\begin{array}{l}\text { Full } \\
\text { investigation } \\
\text { required } \\
\text { before the } \\
\text { trade is } \\
\text { approved }\end{array}$ & $\begin{array}{l}\text { Dependent on the } \\
\text { nature of the trade } \\
\text { once it is approved } \\
\text { it could be } \\
\text { temporary or } \\
\text { permanent and for } \\
\text { a portion or all of } \\
\text { the licence }\end{array}$ \\
\hline
\end{tabular}

Such a system could adapt in response to evidence based on how trades affect other abstractors and the environment and does not rely heavily on the use of sophisticated linked hydrological - water management models that need to be run on short time-scales. There would be regulations that would allow the Environment Agency to prevent trades that had been shown or which are suspected of having adverse effects. Hydrological models would still be used to investigate the 'orange' type trades.

\subsection{Common pool method of trading}

In the common pool method, users would not make pair-wise trades with each other. Instead, users would buy and sell water rights with a catchment manager (such as the Environment Agency or another third party organisation) through a "common pool". The approach used in this research were based on "smart market" techniques. Smart markets are a type of auction in which transactions are made to and from a pool of participants rather than bilaterally between one buyer and one seller. Smart markets are designed to reduce transaction costs and the effect of externalities by means of rapid computerised market-clearing according to well-defined auction rules (Murphy et al, 2000). These processes are operated and monitored by a market manager. Such techniques have been applied successfully in electricity markets and this research investigated how they could be used to manage water shortages during future droughts by facilitating trading.

In the common pool method users place offers to sell or bids to buy quotas of water on a web page, and a catchment manager would clear all trades at once, using a hydrological optimisation, following a regular 
schedule (e.g. weekly or even daily). The optimisation would ensure that environmental flows were satisfied. Users could offer to sell or buy water for future weeks. Within minutes of the market-clearing, users would have firm rights for the immediate period and reasonably reliable rights for the future periods. An illustration of the common pool method is shown in Figure 2.

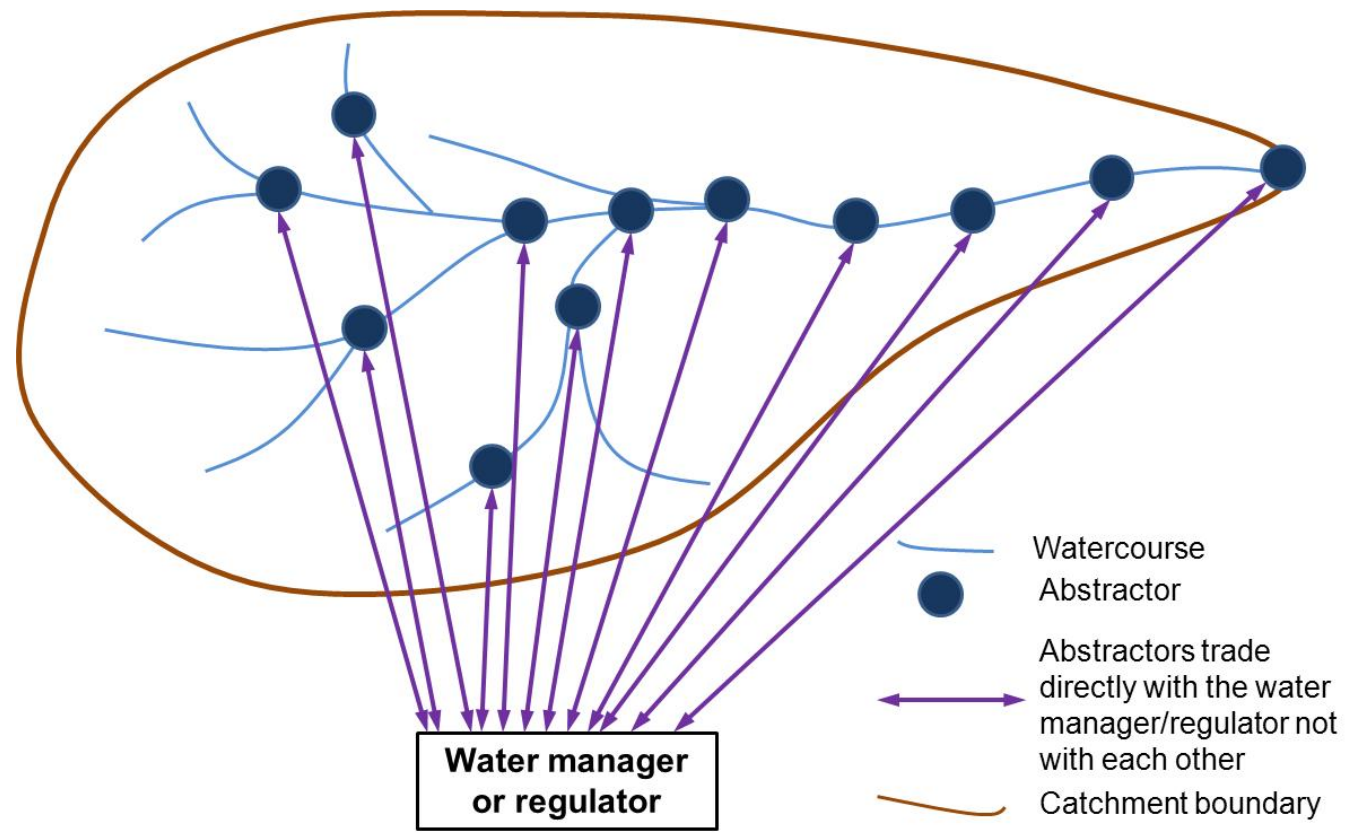

Figure 2 Common pool method of trading within a catchment

\section{Case study catchment}

\subsection{Background}

The Upper Ouse and Bedford Ouse catchment, shown in Figure 3, is located in East Anglia in the east of England. The region has over 1,000 agri-businesses that rely on irrigation to produce $30 \%$ of the UK's potatoes and $25 \%$ of all vegetables and fruit (EEDA, 2008). The catchment is also home to Grafham Water, which covers some $10 \mathrm{~km}^{2}$, and is an important source for public water supply. East Anglia is a dry region with many parts receiving less rain on average than Jerusalem and sub-Saharan Africa, and as a consequence the region is "water stressed" (Anglian Water, 2012). As a result East Anglia is likely to be affected by issues related to over-abstraction earlier than other parts of the country.

Water resources assessments carried out by the Environment Agency indicate that pressures on abstraction, and the associated uncertainty and risks for security of supply in East Anglia, are likely to continue for some time into the future and that climate change will only serve to exacerbate these (Frontier Economics/Anglian Water, 2011). In the Upper Ouse and Bedford Ouse catchment by the year 2050 under an uncontrolled demand scenario there is unlikely to be sufficient water available to meet current levels of abstraction and the environment (Defra, 2011). 
There are approximately 250 licences in the Upper Ouse and Bedford Ouse catchment (Environment Agency, 2009). The distribution of these licences between different sectors, together with the amount of water abstracted by each sector is shown in Table 2 .

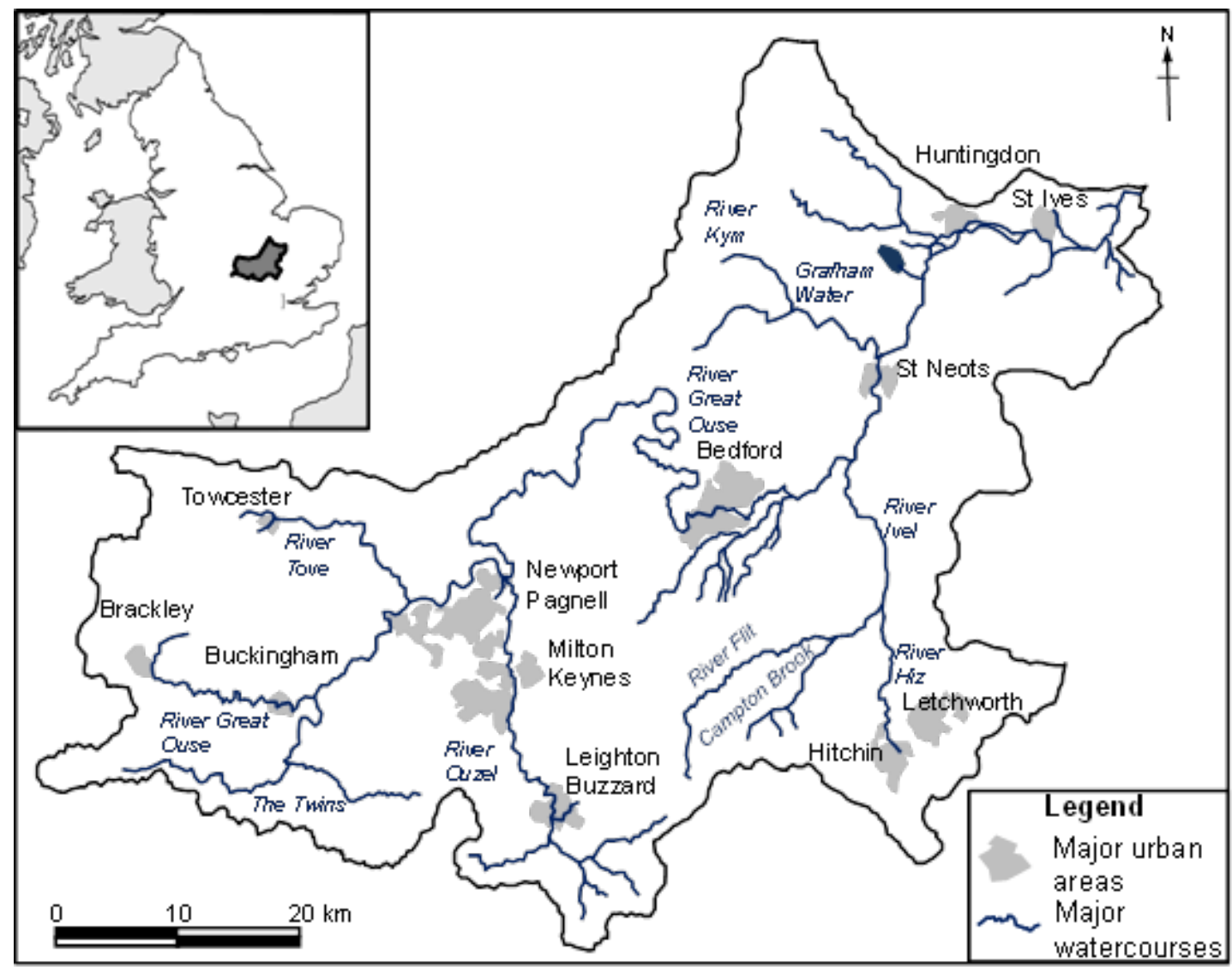

Figure 3 Location of the Upper Ouse and Bedford Ouse catchment

Table 2 Details of the abstraction licences in the Upper Ouse and Bedford Ouse CAMS by sector in 2009

\begin{tabular}{|c|c|c|c|c|}
\hline Sector & $\begin{array}{c}\text { Distribution of the } \\
\text { abstraction licences } \\
\text { between sectors }\end{array}$ & $\begin{array}{c}\text { Volume of water } \\
\text { abstracted (Mllyear) }\end{array}$ & $\begin{array}{c}\text { Volume of water } \\
\text { abstracted by } \\
\text { sector (\%) }\end{array}$ & $\begin{array}{c}\text { Percentage of water } \\
\text { abstracted from } \\
\text { surface water } \\
\text { sources (\%) }\end{array}$ \\
\hline Agriculture & $73.8 \%$ & 1,140 & $1.0 \%$ & $71.8 \%$ \\
\hline $\begin{array}{c}\text { Public water } \\
\text { supply }\end{array}$ & $4.9 \%$ & 102,524 & $93.4 \%$ & $82.7 \%$ \\
\hline $\begin{array}{c}\text { Industry } \\
\text { Electricity } \\
\text { production }\end{array}$ & $12.0 \%$ & 1,780 & $1.6 \%$ & $4.0 \%$ \\
\hline $\begin{array}{c}\text { Fish and } \\
\text { aquaculture }\end{array}$ & $0.5 \%$ & 4,173 & $3.8 \%$ & $100.0 \%$ \\
\hline Other & $0.3 \%$ & 0 & $0.0 \%$ & $0.0 \%$ \\
\hline
\end{tabular}

(Source: Environment Agency, 2009) 
The Upper Ouse and Bedford Ouse catchment is surface water dominated. In 2009 approximately 82\% of the water abstracted in the catchment was from surface water sources.

\subsection{Initial engagement of the stakeholders}

The first phase of the research comprised engaging with stakeholders. Of the 89 stakeholders we contacted, 52 responded; of those, 39 responded positively. The 13 people who responded negatively explained that they were not interested in engaging with the research because they did not feel it was relevant to their organisation or interests. The number of abstractors contacted and the sector in which they operate are shown in Figure 4. The stakeholders were engaged via two focus groups as well as a number of face-to-face and telephone interviews and in total 27 stakeholders were spoken to.

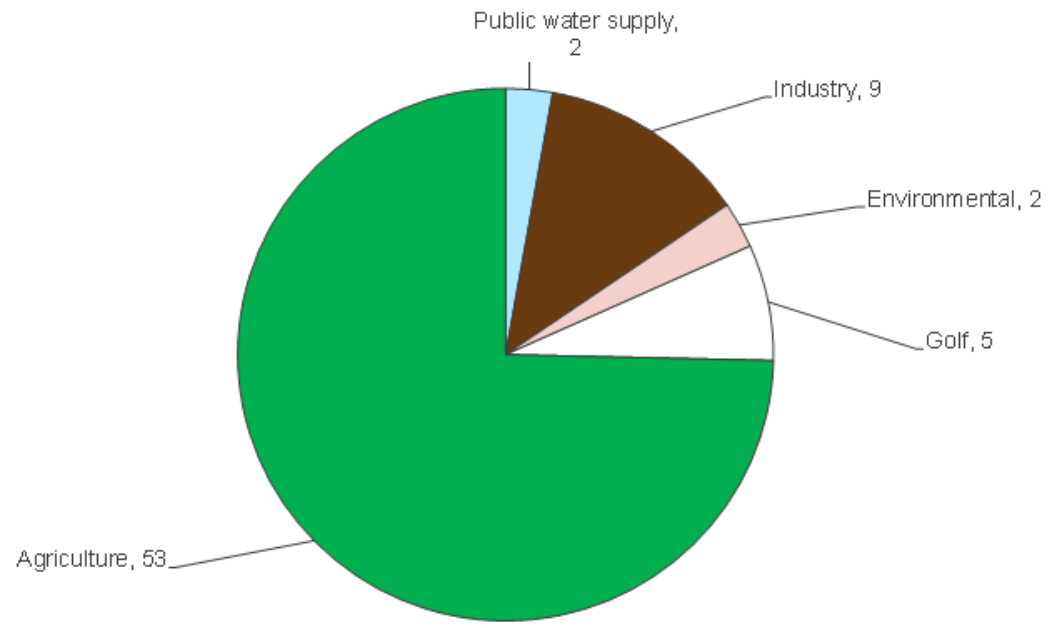

Figure 4 Number of stakeholders engaged from different sectors

We found varied levels of knowledge and understanding of water trading amongst the stakeholders interviewed. Stakeholders were interested in trading, although they did have some concerns.

Losing rights permanently was a concern. Stakeholders had a strong sense that if they had an abstraction licence it is important to keep hold of it even if it is not being used fully. The value of the licence was recognised together with a desire to keep what was regarded as owned by the participant, in particular when the water comes from what is viewed as the abstractors' property "And I think we tend to be quite traditional, it's mine, I've got it and I don't want anything to, you know, I don't want anybody interfering with it." (Focus Group 2).

Transaction costs and time were cited as barriers For example, the one farmer in the middle of a trade said that it was taking a long time to do the paperwork and that it would not be finished till the next season, however, he has been allowed to have the water "lt's just mind-blowing, it's bureaucracy". (Focus group 1).

The lack of knowledge of the price of water raised concerns around transparency and value for money. One abstractor stated that he had been offered a trade but did not want to bid as he had no idea what the price would be. Discussions in an abstractors' group comprising members of the National Farmers Union (NFU) included an example of a farm being offered an abstraction licence for sale but no bid being made as there was uncertainty on what a "sensible" price was for the licence. There is "no idea about what a reasonable offer [for a licence] is" (NFU Regional Abstractors Group). 
There was clear agreement among the farmers that there should be "ring fencing" within sectors for trading as it was felt that industry or water companies would be the winners and agriculture the losers in any system. Ring fencing would entail putting restrictions on certain abstraction licences so that they could only be used for a particular purpose. "Presumably if it was industry they'd want it for a longer basis than an annual basis, whereas agriculture is much more annually orientated, depending on your cropping for that year. Yes, the danger is though they can afford to pay far more for water and that's the way you're going to lose" (Focus Group 1). There were also concerns that the ability of industry and water supply to pay significant amounts of money for abstraction licences would mean that farms would sell their licences and close. This would have a very significant impact on rural communities. However, other abstractors felt that the benefits would be to agriculture rather than to the public water supply: "I think it's going to be for agriculture [who benefits].....I'm struggling to see how public water supply is going to benefit significantly from opening up trading because I just don't.... the scales I think are quite different" (Abstractor 1, water company).

Participants raised concerns related to imbalances in market power when large abstractors, such as public water supply companies trade with smaller abstractors. It was commented that given the relative amounts the water companies and other sectors abstract that the non-water company participants could not see how it would be worth anyone trading between sectors as what was a significant amount of water to one group was not relevant to the other.

The methods via which trading could be implemented were questioned. There was a sense of participants pondering how it could work, especially if everyone wanted water at the same time, which is what happened in a drought. In addition, understanding constraints of location on how trading could work was raised. "If everyone say in this square mile or whatever buys all the licences and you all start abstracting out of the Ouse here from... How does that work because there's only a limited resource? Yes, it's in the same catchment area isn't it?" (Focus group 1).

As part of this initial phase participants were introduced to the two innovative methods of trading in the interviews and focus groups. Most stakeholders expressed general interest in an improved system for trading water licences such as the common pool and improved pair-wise trading. However, many also indicated that they had not had time to fully understand, discuss and digest the systems proposed or that the information provided was not concrete enough to enable them to properly assess the options. Very few stakeholders rejected the idea of water trading for reasons of principle. Those who expressed doubts tended to focus their queries on the way in which the system would work and on how it would fit in with the new system of regulating water abstraction. From this first phase we were able to draw out the factors affecting willingness or not to trade using the proposed methods.

What was clear across the different stakeholders was that there is currently openness to discussions around trading with views not appearing to be polarised either way with regards trading in general or towards one method above another. Water trading was not perceived to be an urgent issue for many abstractors and none had a clear idea of what the price of water might be although many seemed to think that it was likely to be low. The issue of ring fencing (i.e. whether trading could occur across different sectors) was raised by a number of the abstractors, in particular agricultural abstractors. The engagement process allowed the factors that would influence abstractors' decisions about whether to enter the water market, either as a seller or a buyer, to be summarised. These are presented in Table 3. 
Table 3 Factors likely to affect willingness of abstractors to trade water

\begin{tabular}{|c|c|c|}
\hline Factor & Buyer & Seller \\
\hline $\begin{array}{l}\text { Volume of water } \\
\text { traded }\end{array}$ & $\begin{array}{l}\text { For those needing large } \\
\text { amounts of water, there would } \\
\text { be little interest in making } \\
\text { multiple purchases of small } \\
\text { amounts. } \\
\text { Would need to be able to trade } \\
\text { large volumes freely, not just } \\
\text { occasionally or subject to } \\
\text { restrictions. }\end{array}$ & $\begin{array}{l}\text { If the price of water was } \\
\text { perceived to be "low", then } \\
\text { high volumes would need to be } \\
\text { sold to justify the costs } \\
\text { involved in trading. }\end{array}$ \\
\hline Price of water & $\begin{array}{l}\text { Price needs to be lower than the } \\
\text { fine for exceeding licence } \\
\text { conditions. } \\
\text { For abstractors with access to } \\
\text { water from the mains supply, } \\
\text { prices would need to be lower } \\
\text { than that of mains water. }\end{array}$ & $\begin{array}{l}\text { Price would have to be high } \\
\text { enough to justify the costs } \\
\text { involved in trading. }\end{array}$ \\
\hline $\begin{array}{l}\text { Process for } \\
\text { participating in } \\
\text { trading }\end{array}$ & & $\begin{array}{l}\text { The process for providing } \\
\text { information about available } \\
\text { water surpluses and for } \\
\text { completing transactions would } \\
\text { have to be simple and quick, } \\
\text { avoiding additional costs. }\end{array}$ \\
\hline
\end{tabular}

\section{Testing the two innovative trading systems}

\subsection{Introduction to the testing phase}

The testing phase had two key strands which came together in the workshops to demonstrate the two innovative trading systems:

1. Engagement with stakeholders and;

2. Development of trading models for the specific catchment (Upper Ouse and Bedford Ouse).

All the stakeholders who had been engaged with in Phase 1, were sent a letter of thanks together with an update on Phase 2. For Phase 2 the stakeholder engagement consisted of a number of short telephone interviews around costs for water together with the two workshops with abstractors and the Environment Agency. The aim of the interviews was to provide some information for the two trading models being developed, to try to give an indication of what price people might be willing to buy and sell water for. We developed a short interview schedule that covered the following aspects:

- Details of abstraction licences held, water demand and costs to their business of buying a licence; 
- Costs and losses to business associated with reducing water consumption, increasing demand, and lack of water availability.

In total five abstractors were interviewed from a range of sectors including agricultural and industrial. The questions related to value of water and the amount of money abstractors would be willing to pay for water in particular circumstances. Those interviewed found the questions very difficult to answer. We suggest this was partly because of the wording of the questions but also partly to do with the topic area which we found from the first part of the research that many abstractors are unfamiliar with and therefore were not able to answer the questions meaningfully.

\subsection{Demonstration trading models for the Upper Ouse and Bedford Ouse catchment}

To investigate the potential water management impacts of a short-term trading system, a model was built to simulate the current surface water abstraction system and how it could change if short-term trading were pervasive. This model was used to explore how the current system works, and how it could be improved if it were made possible to trade over short periods (i.e. one week). The model represents each surface water abstraction point each week over a possible future drought year. A model that incorporated surface water and groundwater could add further complexity to the design of future trading schemes.

\subsubsection{Improved pair-wise demonstration model}

The improved pair-wise trading model represented the actions of each individual abstractor and the relationships between abstractors to build a collective system-wide view of how short-term licence trading could manifest at the catchment scale. The model accounted for the flow in each part of the river system, and the flow upstream and downstream of each abstractor is estimated each week.

The propensity of abstractors to engage in trading was modelled using abstractor-specific or sector-specific rules and economic demand curves that express how much different amounts of water are worth to the abstractor in a given week. In general, an upstream abstractor will sell water to one or more downstream users if their value of water during that week is sufficiently higher than the upstream abstractor's to overcome the costs of the transaction, although trades may be prevented by specific rules. The model used in this study can be considered a hydro-economic model (Harou et al., 2009) where transactions between individual water rights holders are tracked (Erfani et al., under review) and where rules are imposed to ensure realistic model behaviour.

The improved pair-wise trading simulation included the following assumptions:

- Abstractions - These were based on historical abstraction patterns for the period 2006 to 2011;

value of water - Linear estimates of the value of water ('demand curves') for each abstractor each week of the year were made. These were based on historical monthly water use data for abstractors, an assumed marginal value of water for each sector on how different sectors' water use typically responds to water price;

- Licensing regimes - participants were shown the results of three scenarios: no trading, current licensing system and short-term trading and short-term trading with licence scaling (as investigated in the common pool approach). In this research licences were scaled proportionately to match the surface water flows available; 
- Trading - The model allowed each holder of an abstraction licence to buy or sell water unless an environmental condition on their licence prevents them from doing so. Transactions were limited to a duration of one week in length. The simulated abstractors evaluated whether to abstract based on a weekly economic demand curve for water which quantifies how much the abstractor would be willing to pay per mega-litre. Trades went forward if the difference in water value between a potential seller and buyer is sufficiently large to overcome the cost of the transaction. The trading partners and volumes are selected in such a way to maximise the total economic benefits generated weekly. No abstractor can trade more than half of their average annual use, this rule prevents abstractors from "trading themselves out of business";

- Consumptiveness - The consumptiveness of different sectors was taken from Environment Agency data; and

- Transaction costs - Fixed and variable costs depending on abstractors' relative consumptiveness have been assumed. Fixed costs were set to $10 \%$ of the current trading administrative fee which is currently $£ 135$ (Environment Agency, 2011). The volumetric charges were developed by assuming the regulator could impose a tax on trades where the consumptive use increases.

The model results were used to demonstrate to stakeholders how water management improvements such as the ability to approve trades quickly could facilitate trading of abstraction licences and what effect this could have on abstractors, river flows and storage at the catchment scale.

\subsubsection{Interactive demonstration of the common pool method}

An interactive web-based demonstration of the common pool method was developed to demonstrate how stakeholders could trade water quotas during a potential future drought in the year 2020. The demonstration included an optimization model to clear the market, connected to the market database and a hydrological database, and an associated auction manager's web page to set up auctions and to control the market clearing (Raffensperger et al., 2009). The optimisation calculates the optimal allocation from users' bids, maximising the total value of the water, i.e. the model will try to allocate water to users who bid highest, whilst satisfying the physical and environmental requirements. Following optimisation, the web server calculates trades based on users' initial rights and final allocations.

The interactive demonstration allows users to bid for a water quota on a weekly basis. Within the taxonomy of auctions, the market design was a multi-part bid, multi-round, double-sided periodic auction (Raffensperger et al, 2005). An example of a typical abstractors bidding page is shown in Figure 5 . Participants were asked to bid in five "tranches". The first tranche of water being that they had the greatest requirement for and the fifth tranche being the water that it would be "nice to have". Figure 5 shows that for the first week of the auction, 1 January, the abstractor required $900 \mathrm{Ml}$ for their first tranche (i.e. the water they "really need"), bidding £50/Ml for this. In their second tranche they wanted $700 \mathrm{Ml}$ and bid £25/Ml etc. The clearing price of water for this point in the catchment, based on all the bids and the water balance model, was found to be $£ 25 / \mathrm{Ml}$. The abstractor only pays the clearing price, no matter how high they have bid. In the first week of the auction the abstractor detailed in Figure 5 bid at or above the clearing price for their first and second tranche of water, hence they would have received 1,600 $\mathrm{Ml}$ of water for which they would have paid £25 per Ml. 


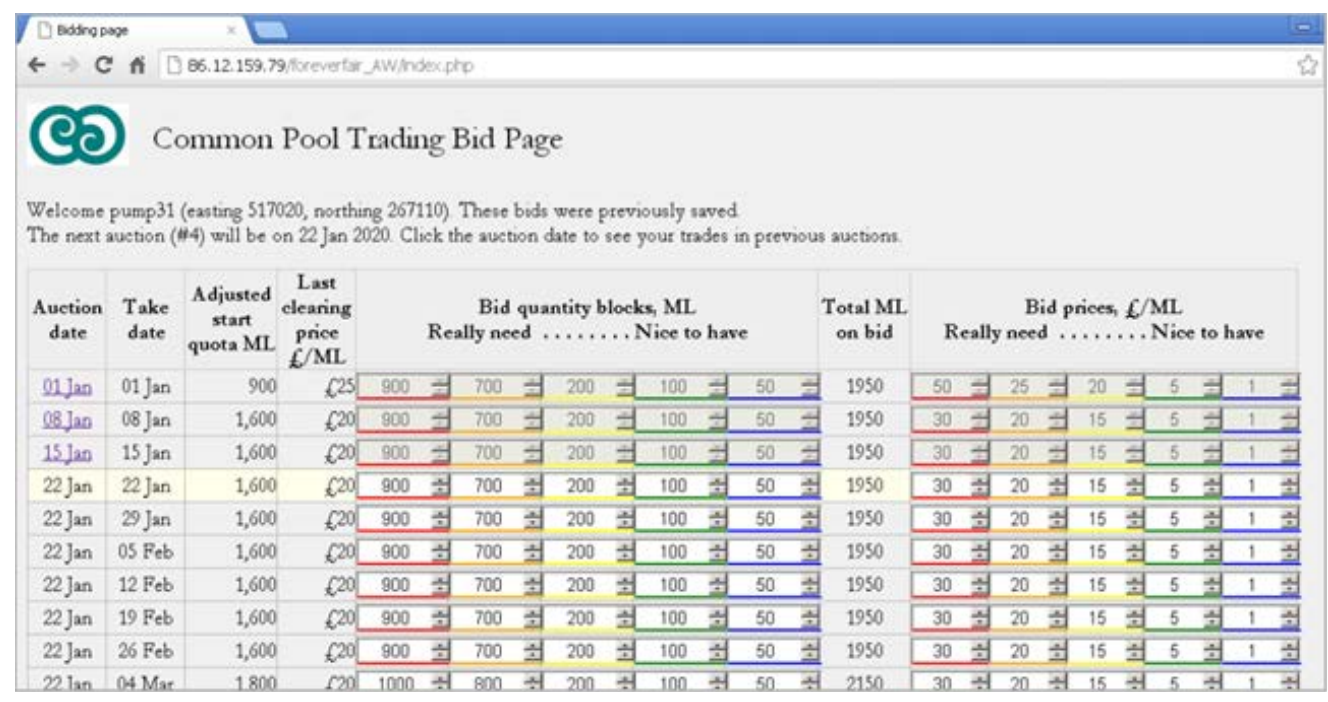

Figure 5 An individual abstractor's bidding page

\section{Trading demonstration workshops}

\subsection{Introduction}

Two workshops were carried out on 9 and 16 October 2012. The aim of the workshops was to gauge users responses to the employment of the improved pair-wise and common pool trading systems in the future in the Bedford Ouse and Upper Ouse catchment. These workshops were aimed at encouraging participants to engage with the approaches and give feedback, they were not designed as controlled experiments, and the sample size was very small. Given this, findings should be regarded as exploratory.

\subsection{Participants}

Participants were invited from the pool of stakeholders with whom we had engaged in Phase 1 of the project. We included all those who had shown an interest in the project together with those who had attended a focus group or taken part in an interview. We approached participants initially via email or letter depending on what was appropriate and then they were followed up by telephone calls until we spoke with the abstractor or were able to leave a message. In total we made contact with approximately 60 abstractors. Of these, 15 attended the workshops, eight at the first workshop and seven at the second workshop. Table 4 details which sectors the participants were from.

Table 4 Details of workshop participants

\begin{tabular}{|l|c|c|}
\hline Sector & Workshop 1 & Workshop 2 \\
\hline Agricultural & 4 & 1 \\
\hline Public water supply & 2 & 2 \\
\hline Industry & 1 & 1 \\
\hline Environmental & & 1 \\
\hline
\end{tabular}




\begin{tabular}{|l|c|c|}
\hline Sector & Workshop 1 & Workshop 2 \\
\hline Regulators & 1 & 1 \\
\hline Researchers & & 1 \\
\hline Total & 8 & 7 \\
\hline
\end{tabular}

\subsection{Method}

The morning was spent on the common-pool method which was explained and demonstrated, then participants had the opportunity to try out the method for "real". Each participant was given a laptop computer and was able to take part in a "live" auction. In the afternoon, participants were introduced to the improved-pair wise model through a presentation. This was followed by small group discussions around model outputs that simulated what might happen if this approach were implemented in the Upper Ouse and Bedford Ouse catchment.

Participants had to fill in three short questionnaires covering their views on:

1. Trading before the workshop commenced

2. The improved pair-wise approach after an example of its application

3. The common pool approach after the interactive demonstration

\subsection{Findings}

\subsubsection{Views on trading prior to the workshop}

Before the workshops it was found that overall, stakeholders had a positive interest in trading, but those who were positive had questions that needed to be addressed for them to feel comfortable with water trading, although there were some negative comments. It was found that to have more meaningful discussion more knowledge and engagement with trading and its role in water management was needed.

\subsubsection{Views on the improved pair-wise trading approach}

Participants generally felt comfortable with this system as it was perceived as an incremental improvement of the current system aimed primarily at allowing short-term trading. Only two comments on the questionnaires suggested that the participants felt that improved pair-wise trading system had greater transparency than the current system, but the "fairness" of this approach was seen to be dependent on how scaling of licensed abstractions would be introduced in a drought. The grandfathering of existing licence conditions, i.e. whether previously high reliability licences under current system would remain so under a shares licensing system was seen as important. The idea of pre-approved trades was welcomed by participants, on the condition that studies were carried out to show that these were not detrimental to the environment. The use of web-based bulletin boards that help put buyers and sellers together was seen as a benefit. In addition it was felt that relationships between abstractors would develop over time. It was also felt that abstractors would have control over their licences and be able to plan ahead. The model's ability to use flexible rules to represent water user actions underscored the question of how privatised natural monopoly water companies would engage with the potentially lucrative practice of short-term water trading. 


\subsubsection{Views on the common pool trading approach}

During the workshop there was time to carry out four rounds of the auction. This was sufficient to provide the participants with a good idea as to how the technique worked.

The reaction of the participant to the common pool method was varied. Twelve of the fifteen participants commented on issues related to "fairness". Some participants felt that "big players" had the potential to dominate and that rules would be needed to ensure fairness. This was a particular concern amongst agricultural abstractors who raised the issue of "ring-fencing", i.e. keeping the trades within sectors, although implementing ring-fencing would undermine overall trading and would reduce the flexibility of the market. Respondents were concerned that water for domestic consumption is considered to have a higher value than agriculture, and given its dominance in the catchment the water supply company would be able to set the price of water across the catchment.

The participants discussed their potential engagement with the approach and were positive but cautious, suggesting they might engage with a simpler system. Of the different sectors, the public water supply sector felt if certainty of supply was guaranteed then they could use the system. The Royal Society for the Protection of Birds (RSPB) felt it could help the management of their wetlands and potentially provide an income stream for them. The issue of the governance of water was raised; it was felt that stakeholders should be engaged with the planning process and the setting of environmental flows and that this common pool approach might encourage more collective responsibility for managing the water in the catchment.

\section{Discussion}

The abstraction regime in England and Wales was historically based on common law riparian rights, with "riparianism" considered to be an adequate basis for the management of water until the introduction of recent reforms. In 2011 Defra investigated the unmet demand for abstraction licences in catchments across England and Wales. That study found that only a small number of sectors currently face problems with unmet demand, but the situation is expected to worsen in the future owing to climate change and population growth (Defra, 2011d). However, new users have difficulty entering the market in over-licensed or overabstracted catchments and new abstractors are often forced to buy or lease a property that has an existing abstraction licence.

For trading of abstraction licences to be active, a catchment needs a degree of both resource stress and unmet demand (either on a permanent or temporary basis). If plenty of water is available, trading will not take place (Defra, 2011c). An active market within a hydrological or hydrogeological area requires a sufficient number of abstraction licence holders, and also depends on transaction costs.

The development of water markets, which commenced in the late 1980s in Australia has occurred through a gradual, learning and adaptive process, allowing stakeholders to "be brought along for the journey" through participation (in regionally controlled situations) in the market (Slayter and Cvijanovic, 2012). In addition, Australian water markets have been developed in consultation with state and territory governments at both policy and implementation levels, and feedback loops were established to ensure that lessons learnt were captured and amendments to policy enacted accordingly (in a timely manner to respond to market needs). Regular reviews of policy, implementation and trends have also been a key feature of water markets operating in Australia.

Australia has refined its approach over a 20 year period. This has been found to help to manage uncertainty and the concerns of stakeholders (National Water Commission, 2011). Water trading in England and Wales 
is also likely be introduced incrementally. There needs to be market rules and complementary policies to prevent adverse environmental and social impacts. In the UK, Defra is committed to implementing the WFD by 2025 which may increase environmental flows in currently over-abstracted catchments, if this can be achieved without disproportionate cost.

In many cases the diversity of water needs increases the effectiveness of trading. It is important to note that in Australia where water trading was introduced some 20 years ago, water markets are continuing to develop and difficulties are still being ironed out (Slayter and Cvijanovic, 2012). In Australia water markets have been used extensively during recent droughts as a key tool to manage scarce water resources (National Water Commission, 2011). However, this research suggests that whilst stakeholders in England are open to the opportunities afforded by water trading there is still much work to do before it can be implemented.

\section{Conclusions}

There is widespread lack of knowledge and awareness of water trading across all types of stakeholders in England. In the groups who engaged with the project we did not find entrenched views; there was neither outright rejection nor committed support for increased trading in water or a new system to facilitate it. Even people who did not want to participate in the research when invited indicated that this was because they could not see its relevance (often because the quantities of water they used were "small"), not because they were opposed to it.

The idea of sectoral "ring fencing" was raised by some abstractors. There was a perception that farmers would lose out to larger abstractors such as water companies. Owing to the relatively small size of agricultural abstraction in the catchment some suggested larger abstractors would not be willing to make small trades with farmers.

There was general agreement that the common pool and improved pair-wise trading systems provided more flexibility than the current licensing system in facilitating short-term trading of water. The use of web pages and maps showing where abstractors are willing to buy and sell water was seen as useful by most of the stakeholders engaged in the research.

Stakeholders expressed some concern that under the proposed trading systems water would be allocated to sectors with higher economic value. The question of the price of water was an issue. In the common pool method users had difficulty in choosing bids. This difficulty had to do with the associated lack of price history, the novelty of the market and also users' lack of knowledge about their own value for water.

The introduction of short-term, more flexible trading systems implies a change of mind-set by abstractors and will require a period of learning. For these systems to be successful market participants need to have sufficient confidence that the rules are fair and protect their interests. If models are central to water trading practice, as in the common pool approach, the underlying models must be shown to be sufficiently accurate. If abstractors are not convinced that these conditions will be realised, they are unlikely to engage with trading.

This research was based on engagement with a limited number of abstractors over a short period of time. Raw water is currently relatively inexpensive in England and Wales and consequently many abstractors other than public water supply companies, farmers and power companies do not place water high on their agenda. To conclude, broader engagement over a sustained period would obtain more definitive insight into stakeholders' views on water trading. 


\section{References}

Anglian Water (2012). About us [WWW] http://www.anglianwater.co.uk/about-us/ (accessed 15 December 2012)

Cunningham, R. (2002). Reform of water resource control in England and Wales, Journal of Water Law, 2002, Vol 13, issue 1, pp35-44

Department for the Environment Food \& Rural Affairs (Defra). (2011a) Water for life market reform proposals (Vol. December).

Department for the Environment Food \& Rural Affairs (Defra). (2011b) Water for life, December 2011.

Department for the Environment Food \& Rural Affairs (Defra). (2011c) Characterising potential water abstraction licence markets: Phase 2 - catchments for trading promotion, August 2011.

Department for the Environment Food \& Rural Affairs (Defra). (2011d) Characterising potential water abstraction licence markets, March 2011.

Department for the Environment Food \& Rural Affairs (Defra). (2012). Impacts of abstraction reform options on non-public water supply abstractors http [WWW] www.defra.gov.uk/abstraction-reform/files/randdnonpws-flyer.pdf (accessed 12 February 2013)

East of England Development Agency (EEDA), Environment Agency, National Farmers Union, UK Irrigation Association (2008) A fair share of water for agriculture: A strategy for irrigation in Eastern England; A strategy to ensure that agriculture receives a fair share of water resources and uses it in a sustainable and efficient manner.

Environment Agency (2009). Abstraction statistics database.

Environment Agency (2005) The Upper Ouse and Bedford Ouse Catchment Abstraction Management Strategy.

Environment Agency (2010a) Fact sheet WR-252 How time limits on abstraction licences work.

Environment Agency (2010b) Drought plan for Anglian Central Region, 2010.

Environment Agency (2011) A guide to water rights trading published, October 2011.

Environment Agency (2012) Restoring Sustainable Abstraction (RSA) programme, July 2012

Environment Agency (2012) Abstraction licence restrictions: Hands off flow and hands off level conditions, August 2012

Environment Agency and Ofwat (2012) The case for change: Reforming water abstraction management in England.

Erfani, T., Huskova, I. and Harou, J.J. (under revision) Tracking trade transactions in water resource systems - A node-arc optimization model formulation, Water Resources Research.

Harou, J.J., Pulido-Velazquez, M.A., Rosenberg, D.E., Medellin-Azuara, J., Lund, J.R., Howitt, R. (2009) Hydro-economic models: Concepts, design, applications and future prospects., Journal of Hydrology, $375,334-350$.

Frontier Economics and Anglian Water (2011) A right to water? Meeting the challenge of sustainable water allocation, Main report, February 2011 
Murphy, J. J., Dinar, A., Howitt, R. E., Rassenti, S. J., \& Smith, V. L. (2000). The design of "smart" water market institutions using laboratory experiments, Environmental and resource economics, 17(4), 375394.

National Water Commission (2011) Water markets in Australia: a short history, NWC, Canberra, Australia.

Raffensperger, J. F., Milke, M., (2005) A design for a fresh water spot market, Water Science \& Technology: Water Supply, 5(6), 217-224, 2005.

Raffensperger, J. F., Milke, M.W. and Grant Read, E. (2009) A deterministic smart market model for ground water, Operations Research, v57, n6, Nov-Dec 2009, pp. 1333-1346.

Slayter, T. and Cvijanovic, T. (2012) Personal communication with Tony Slatyer First Assistant Secretary and Tanja Cvijanovic of the Water Reform Division Department of Sustainability, Environment, Water, Population and Communities, Australia, 28 September 2012.

Sowter, P. and Howsam, P. (2008) The Water Act 2003 and sustainable abstraction, Journal of Water Law, 2008, Vol 19, issue 1, pp33-36

\section{Acknowledgements}

The authors would like to express their gratitude to Anglian Water and Department for Environment, Food and Rural Affairs (Defra) who financed this research and especially Jean Spencer who provided invaluable support and guidance. The authors also wish to acknowledge the valuable comments of the Working Group that steered this research which included: Anglian Water, University of Cambridge Programme for Sustainability Leadership, Defra, NFU, the Royal Agricultural Society of England, Natural England, the Environment Agency, Ofwat, WWF-UK, Association of Drainage Authorities, Cranfield University, Atkins, the RSPB and the Broads Authority and also all the stakeholders in the region who were engaged as part of the research.

\section{Disclaimer}

This paper reflects the views of the authors and should not be construed to represent the views or policies of Defra, Anglian Water or any other members of the Working Group that provided either funding or advice to the authors. 